\title{
Aplicações de tecnologias pós-colheita para bananas 'Prata-Anã' produzidas em Roraima
}

\author{
Marcos A. de S. Prill ${ }^{1}$, Leandro T. B. C. Neves², André J. de Campos ${ }^{3}$, \\ Samuel Silva ${ }^{4}$, Edvan A. Chagas ${ }^{5} \&$ Wellington F. Araújo ${ }^{6}$
}

\begin{abstract}
RESU M O
Neste trabalho objetivou-se manter a qualidade e aumentar o tempo de prateleira durante a pós-colheita de bananas 'Prata-Anã' e se avaliou a eficiência do armazenamento refrigerado (AR) e da atmosfera modificada (AM) pelo uso de embalagens plásticas de polietileno de baixa densidade (PEBD), do vácuo e da utilização de sachê adsorvedor de etileno. O s tratamentos foram: T1: Controle (sem embalagem, sistema de adsorção de etileno e sem vácuo); T2: Embalagem de polietileno de baixa densidade (PEBD ); T3: PEBD + adsorvedor de etileno; T4: PEBD + vácuo e T5: PEBD + adsorvedor de etileno + vácuo. As análises foram realizadas em intervalos de 5 dias após a colheita, até 35 dias de AR. Verificou-se que os frutos submetidos à embalagem de PEBD apresentaram as menores áreas de lesão na casca, as menores concentrações de etileno, os menores incrementos de acidez titulável (AT) e comportamento normal/ manutenção dos valores de $\mathrm{pH}$ o que, possivelmente, proporcionou os maiores teores de açúcares totais e redutores ao final do período experimental; concluiu-se,então, que a combinação do uso da embalagem de PEBD com os sachês adsorvedores de etileno resultou no retardamento do processo de maturação dos frutos de banana 'Prata-Anã' proporcionando, comercialmente, a extensão da vida útil dos frutos em até 30 dias após a colheita.
\end{abstract}

Palavras-chave: Musa sp., atmosfera modificada, etileno, vácuo

\section{Application of postharvest technologies for bananas 'Prata-Anã' produced and marketed in the Roraima - Brazil}

\begin{abstract}
In order to keep the quality and increase the shelf-life during the postharvest of bananas 'Prata-Anã', the efficiency of cold storage (CS), the modified atmosphere (MA) by the use of low density polyethylene (LDPE) plastics bags, vacuum and use of sachet adsorption of ethylene was evaluated. The treatments were: T1: control (no packaging, system of ethylene adsorption or vacuum), T2: LDPE; T3: LDPE + system of ethylene adsorption; T4: LDPE + vacuum and T5: LDPE + system of ethylene adsorption + vacuum. Analysis were performed every 5 days after harvest, up to 35 days. It was verified that the fruit under LDPE bags showed the smallest areas with skin lesions, the lowest ethylene concentration, the lowest increments of titratable acidity (TA) and normal behavior/maintenance of pH levels. This possibly resulted in the highest contents of total and reduced sugars at the end of the experiment. Thus, it was concluded that the combined use of LDPE bags with the ethylene adsorbents sachets resulted in delaying in the process of bananas 'Prata-Anã' ripening, resulting, commercially, in the extension of shelf-life of banana for at least 30 days after harvest.
\end{abstract}

Key words: Musa sp., modified atmosphere, ethylene, vacuum

\footnotetext{
${ }^{1}$ ADERR, R. Cel Mota, 1142, Centro, CEP 69301-120, Boa Vista, RR. E-mail: marcosprill@bol.com.br

2 DFT/U FRR, Pos-D oc em Food Science, Campus Cauamé BR 174 KM 12, M onte Cristo, Boa Vista, RR. E-mail: rapelbtu@hotmail.com

${ }^{3}$ Embrapa Roraima, Rod. BR 174, Km 08, Distrito Industrial, Boa Vista, RR. Bolsista de Produtividade em Pesquisa do CN Pq. E-mail: edvan.chagas@embrapa.br.

4 UEG/UnU CET, BR 153 n.3105, CEP 75132-400, Campus Henrique Santillo, Anápolis, GO. E-mail: andre.jose@ueg.br

${ }^{5}$ Graduando em Agronomia UFRR, Campus Cauamé BR 174 KM 12, M onte Cristo, Boa Vista, RR. E-mail: samuel.agro@hotmail.com

${ }^{6}$ DSEA/U FRR, Doutor em Irrigação, Campus Cauamé BR 174 KM 12, Monte Cristo, Boa Vista, RR. E-mail: wellington@cca.ufrr.br
} 


\section{INTRODUÇÃO}

De acordo com a Organização das Nações Unidas (ONU) o Brasil foi, em 2008, o $4^{\circ}$ maior produtor mundial de banana (Musa sp.), com aproximadamente 7 milhões de toneladas, logo atrás da China, Filipinas e Índia, com 8.042.702, 8.687.624 e 26.217.000 toneladas, respectivamente (FAO, 2009). A produção brasileira de banana está distribuída por todo o território nacional, sendo a região Nordeste a maior produtora (34\%), seguida das regiões Norte (26\%), Sudeste (24\%), Sul (10\%) e Centro-Oeste (6\%). No norte do País existem mais de 110.000 ha de pequenos cultivos, cerca de $60 \%$ dos quais em sistemas agrofamiliares com produção anual de 1,7 milhão de toneladas em 2005 (Alves et al., 2007).

Em Roraima, a bananicultura abrange todos os 15 municípios, sendo que a produção do Estado abastece 75 e 55\% dos mercados em Boa Vista, RR, e Manaus, AM, respectivamente (Moreira et al., 2007).

Do momento em que são colhidas até o consumo, as bananas sofrem injúrias mecânicas que, de acordo com a sensibilidade, podem causar danos que comprometerão a qualidade final dos frutos. Campos et al. (2003) verificaram, em experimento com banana 'Nanicão' que, devido ao excessivo amadurecimento e despencamento dos frutos, juntamente com a perda de massa, os prejuízos chegaram a 42,41 e 41,72\% no período de transporte nos estados de Santa Catarina e Mato Grosso, respectivamente, mesmo o transporte sendo sob AR. Desta forma, a ausência de processos tecnológicos que visem à manutenção da qualidade dos frutos durante a produção, colheita e pós-colheita pode desencadear perdas irreparáveis no produto final, levando-o à depreciação tanto no valor sensorial, nutritivo e microbiológico quanto no próprio valor econômico (Antunes et al., 2003).

Aliada à elevada sensibilidade a danos mecânicos, a sustentabilidade à senescência impede a comercialização dos frutos em locais distantes das áreas produtivas, principalmente quando não se utiliza cadeia do frio (Sales et al., 2004). Dentre outras, as alternativas para diminuição das perdas e da redução acelerada da qualidade são o uso do armazenamento refrigerado (AR), da atmosfera modificada (AM), da tecnologia de inibição da ação do etileno, passíveis de serem aplicadas de maneira isolada ou combinadas entre si (Neves et al., 2008). O AR é essencial para tornar lenta a deterioração química, física e fisiológica dos produtos frescos (Viviani \& Leal, 2007).

Associado ou não ao AR pode-se utilizar o polietileno de baixa densidade (PEBD) como embalagem haja vista que se trata de um dos filmes que têm sido utilizados para proporcionar a AM, apresentando permeabilidade seletiva aos gases emitidos durante a estocagem de frutos possibilitando, também, redução da transpiração (Pinto et al., 2006). Com o objetivo de potencializar os efeitos no retardamento do metabolismo póscolheita pode-se associar esses métodos ao sistema de inibição do etileno. No que tange aos sistemas de inibição do etileno, tem-se utilizado o sachê adsorvedor de etileno, que oxida esse fitorregulador liberado pelo fruto durante o amadurecimento prolongando a fase preclimatérica e a vida pós-colheita (Rocha, 2005). Com isto, a execução do presente trabalho é relevante para a cadeia produtiva de bananas 'Prata-Anã' em Roraima permitindo, desta forma, maior qualidade e confiabilidade do produto para o mercado consumidor local e regional.

Objetivou-se, neste trabalho, avaliar a eficiência do armazenamento refrigerado (AR), da atmosfera modificada (AM) pelo uso de embalagens plásticas de polietileno de baixa densidade (PEBD) do vácuo e da utilização de sachê adsorvedor de etileno.

\section{Material e MÉTODOS}

O experimento foi realizado com frutos da bananeira 'PrataAnã' no período de janeiro a fevereiro de 2010, colhidos na empresa Roraima Agrofrutas (latitude 250’06" N e longitude $\left.60^{\circ} 40^{\prime} 28^{\prime \prime} \mathrm{W}\right)$. As análises foram realizadas no Laboratório de Tecnologia de Alimentos (LTA) da Universidade Federal de Roraima(UFRR).

Após colhidos, os cachos foram transportados para a "packing house" da empresa Roraima Agrofrutas, onde passaram por pré-limpeza eliminando-se a raquis e os restos culturais; em seguida, realizou-se o pré-resfriamento a $20 \pm 2$ ${ }^{\circ} \mathrm{C}$, durante 30 min (imersão em tanque com água, sulfato de alumínio e cloreto de cálcio a $2 \%$ ) e a despalma; só então os frutos foram transportados em caixas plásticas de $20 \mathrm{~kg}$ até o LTA/UFRR, onde foram imersos em solução de hipoclorito de sódio a 2,5\% $\mathrm{L}^{-1}$ de água, por $10 \mathrm{~min}$; o enxague e a secagem dos frutos foram realizados ao ar atmosférico do LTA $\left(22 \pm 1{ }^{\circ} \mathrm{C}\right.$ e $75 \pm 3 \%$ de U.R.) pelo tempo de $30 \mathrm{~min}$.

Os frutos foram uniformizados em buquês (de 3 a 5 dedos) apresentando, em média, $447 \pm 50 \mathrm{~g}$ de massa fresca medindo de $0,16 \pm 0,02$ m de comprimento e $0,133 \pm 0,02 \mathrm{~m}$ de diâmetro e a coloração 1 na escala adotada pela PMHB-PIF (2006) foram selecionados e padronizados pelo tamanho e pela ausência de danos/defeitos visuais; cada buquê se constituiu em uma unidade amostral.

Inicialmente, as bananas recém-colhidas foram caracterizadas, quanto ao: $\mathrm{pH}$ médio de 5,50, sólidos solúveis médio de $3,55^{\circ}$ Brix e acidez titulável média de 2,38\% de ácido málico $100 \mathrm{~g}^{-1}$ de polpa. Os tratamentos foram assim dispostos: T1Controle (sem embalagem, sistema de adsorção de etileno e sem vácuo); T2-Embalagem de polietileno de baixa densidade (PEBD) com 0,010 mm de espessura (único lado), área de permeabilidade de $805 \mathrm{~cm}^{3}$, taxa de permeabilidade a oxigênio $\left(\mathrm{TPO}_{2}\right)$ de $11.234 \mathrm{~cm}^{3} \mathrm{~m}^{-2} \mathrm{~d}^{-1} \mathrm{e}$ taxa de permeabilidade a gás carbônico $\left(\mathrm{TPCO}_{2}\right)$ de $36.705 \mathrm{~cm}^{3} \mathrm{~m}^{-2} \mathrm{~d}^{-1}$; T3-PEBD + adsorvedor de etileno (sachê de $10 \mathrm{~g}$, contendo permanganato de potássio, marca Always Fresh ${ }^{\circledR}$, do fabricante Soloeste); T4-PEBD + vácuo (-600 mmHg); e T5-PEBD + adsorvedor de etileno + vácuo.

Após os tratamentos as unidades experimentais foram armazenadas em câmara frigorífica a $12 \pm 1{ }^{\circ} \mathrm{C}$ e U.R. de $93 \pm 2 \%$, durante 35 dias. Os dados foram coletados em triplicata, em intervalo de 5 dias a partir da data da colheita até os 35 dias de $\mathrm{AR}$; sempre $12 \mathrm{~h}$ antes das análises os frutos eram retirados do $A R$ visando à elevação da temperatura dos frutos até o equilíbrio com o ambiente do LTA $\left(22 \pm 1^{\circ} \mathrm{C}\right.$ e $75 \pm 3 \%$ de U.R. $)$.

Em cada dia de análise foram avaliados os seguintes parâmetros: 
1. Acidez titulável (AT): determinada por titulometria de neutralização, pela titulação de $10 \mathrm{~g}$ de polpa triturada, homogeneizada e diluída para $100 \mathrm{~mL}$ em água destilada, com solução padronizada de hidróxido de sódio a $0,1 \mathrm{~N}$, com ponto de viragem no $\mathrm{pH} 8,2$, cujos resultados foram expressos em \% de ácido málico $100 \mathrm{~g}^{-1}$ de polpa (Brasil, 2008);

2. $\mathrm{pH}$ : determinado com pHmetro digital Marca Gehaka, Modelo PG1800, diretamente na polpa da banana (Brasil, 2008);

3. Lesões na casca: avaliação da existência de lesões na casca dos frutos as quais foram medidas em centímetros; a partir daí, foram atribuídas notas variando a gravidade das lesões e conforme a escala subjetiva de valores adaptados de Sanches et al. (2004): 1: sem lesão; 2: lesões muito leves (até $0,5 \mathrm{~cm}$ na maior extensão); 3: lesões leves ( $>0,5 \mathrm{~cm}<1,5 \mathrm{~cm}$ na maior extensão); 4: lesões médias $(>1,5<2,5 \mathrm{~cm}$ na maior extensão); 5: lesões graves (> 2,5 cm na maior extensão); 6 : lesões graves (> 2,5 cm com sintomas microbiológicos);

4. Açúcares totais e redutores: foram determinados segundo a metodologia de Nelson (1944) e os resultados expressos em mg de glicose $100 \mathrm{~g}^{-1}$ de polpa;

5. Concentração de etileno: com o auxílio de seringas hipodérmicas foram coletadas amostras de $5 \mathrm{~mL}$ da atmosfera gasosa das embalagens de PEBD, de cada repetição, de todos os tratamentos com embalagem porém para os frutos do tratamento controle (sem embalagem) foi acondicionado $1 \mathrm{~kg} \pm$ $55 \mathrm{~g}$ de frutos (na repetição), em recipientes herméticos com capacidade unitária de $5,0 \mathrm{~L}$ durante $1 \mathrm{~h}$ a $22,0 \pm 1,0^{\circ} \mathrm{C}$. Decorrido este período foram coletados, com auxílio de seringa hipodérmica, 5,0 mL da atmosfera gasosa de cada recipiente para dosagem do etileno e do $\mathrm{CO}_{2}$. A concentração de etileno foi quantificada por cromatografia em fase gasosa utilizandose cromatógrafo a gás marca Varian ${ }^{\circledR}$ modelo 3300 equipado com coluna de aço inox 1/8" preparado com Porapak® $\mathrm{N} \mathrm{e}$ detector de ionização de chama. Os resultados foram expressos em ppm de etileno.

$\mathrm{O}$ experimento foi realizado em delineamento inteiramente casualizado (DIC) com esquema fatorial 5 x 7 (tipos de acondicionamento $\mathrm{x}$ dias de análises) com 3 repetições e cada repetição composta por 2 unidades amostrais. Feita a análise exploratória dos dados, constatou-se que os mesmos seguiam distribuição normal, os erros eram independentes e apresentavam homocedasticidade. Assim, os dados foram submetidos à análise de variância pelo teste $\mathrm{F}$ e a comparação de médias efetuada pelo teste de Tukey a $5 \%$ de probabilidade.

\section{RESULTADOS E DISCUSSÃO}

Observou-se, ao longo do período de armazenamento refrigerado (AR) que os frutos apresentaram incrementos no teor de acidez titulável (AT) (Figura 1), tendência considerada normal, segundo Botrel et al. (2002) porém este incremento foi mais acentuado naqueles frutos nos quais não houve controle da ação do etileno.

Ressalta-se que ocorreu incremento significativo nos valores de AT nos frutos acondicionados na presença do sachê adsorvedor, independentemente do vácuo, somente após o $15^{\circ}$ dia de AR. Também se pôde constatar que os menores

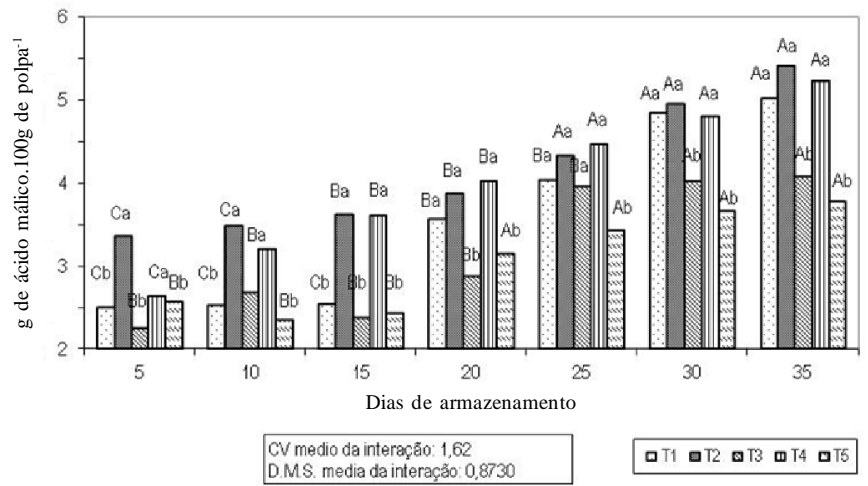

Obs.: T1 - Controle; T2 - Embalagem de polietileno de baixa densidade (PEBD); T3 - embalagem de PEBD + adsorvedor de etileno; T4 - embalagem de PEBD + vácuo; e T5 - embalagem de PEBD + adsorvedor de etileno + vácuo. As médias seguidas das mesmas letras maiúsculas nos dias de armazenamento e minúsculas entre os tratamentos, não diferem entre si em nível de 0,05 de probabilidade Tukey

Figura 1. Acidez titulável em bananas 'Prata-Anã' quando submetidas a diferentes tratamentos

picos de AT, ao final do período experimental, ocorreram justamente nesses frutos fato devido, possivelmente, às menores quantidades de etileno livre no interior dessas embalagens (Figura 6). Por outro lado, dos 5 aos 20 dias de experimento os maiores teores de AT foram detectados nos frutos embalados sem o sachê adsorvedor. Atribuiu-se tal comportamento ao fato de a embalagem funcionar como uma membrana que reteve o etileno concentrado junto aos frutos fazendo com que seu processo de maturação não fosse retardado, confirmando os maiores teores de açúcares totais e redutores nesses frutos.

A partir dos 25 dias foram verificados os menores teores de AT nos frutos submetidos à presença do sachê adsorvedor combinado com o vácuo. Desta forma, esses frutos se apresentaram em estádio de maturação menos avançado que os demais, evoluindo durante o amadurecimento, embora de forma mais lenta, o que permite pressupor maior longevidade para os frutos embalados em PEBD com o sachê adsorvedor e submetido ao vácuo.

De maneira geral, ficou patente comportamento de redução dos valores do $\mathrm{pH}$ (Figura 2) embora com certa oscilação durante o período de amadurecimento/senescência dos frutos;

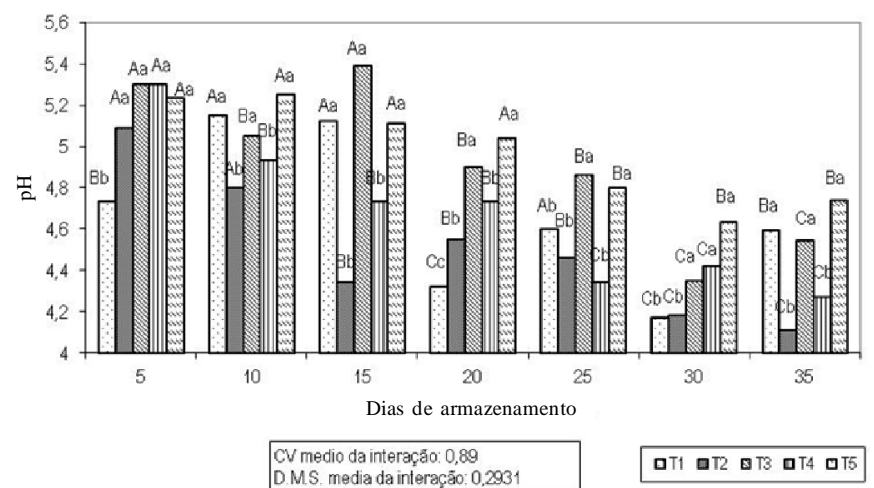

T1 - controle; T2 - embalagem de polietileno de baixa densidade (PEBD); T3 - embalagem de PEBD + adsorvedor de etileno; T4 - embalagem de PEBD + vácuo e T5 - embalagem de PEBD + adsorvedor de etileno + vácuo. As médias seguidas das mesmas letras maiúsculas nos dias de armazenamento e minúsculas entre os tratamentos, não diferem entre si em nível de 0,05 de probabilidade Tukey

Figura 2. Potencial hidrogeniônico $(\mathrm{pH})$ em bananas 'Prata-Anã' quando submetidas a diferentes tratamentos 
resultados semelhantes foram observados por Silva et al. (2006) que, trabalhando com climatização de bananas, verificaram que a partir do momento em que o fruto se tornou maturo, foram constatadas elevações nos valores de $\mathrm{pH}$ fato também observado no presente trabalho para os frutos do tratamento controle, em que não foi utilizada embalagem plástica. Para esses frutos verificou-se a elevação no $\mathrm{pH}$ aos 5 e 10 dias após a colheita, manutenção aos 15 , queda a partir 20 e nova elevação aos 35 de A.R., confirmando o estádio de plena senescência desses frutos, ao final do experimento.

Para os demais frutos embalados em PEBD o comportamento foi semelhante mas esses resultados foram observados em tempos distintos referido comportamento pode ser atribuido à solubilização de ácidos orgânicos e à própria característica normal do metabolismo dos frutos. Portanto se levando em consideração outras variáveis analisadas, ficou evidente o efeito positivo do sachê adsorvedor de etileno em reduzir o metabolismo dos frutos, independentemente ou não do emprego do vácuo.

A ausência da embalagem, que possivelmente permitiu a maior perda de água, implicou na maior intensidade das modificações indesejáveis nos frutos como, por exemplo, o aparecimento de lesões na casca (Figura 3). Assim sendo, o uso de filmes plásticos aumentou a proteção dos frutos contra o aparecimento de lesões na casca, permitindo a ampliação do período de comercialização.

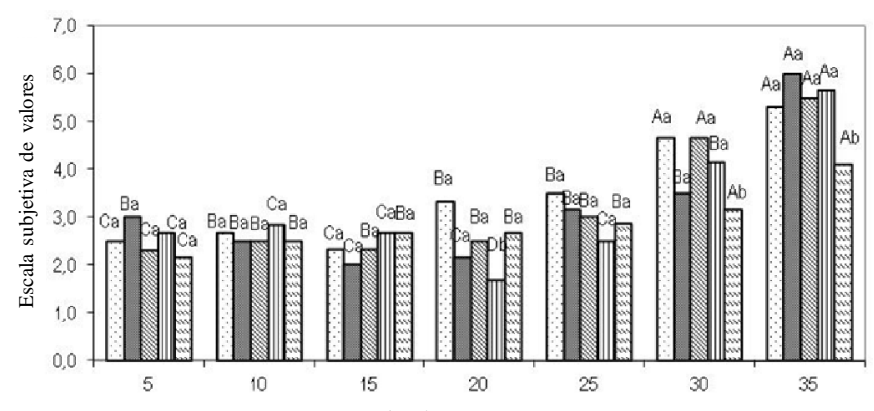

CV mediada interayta 2080 armazenamento CV media da interąăa 2,88

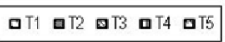

T1 - controle; T2 - embalagem de polietileno de baixa densidade (PEBD); T3 - embalagem de PEBD + adsorvedor de etileno; T4 - embalagem de PEBD + vácuo; e T5 - embalagem de PEBD + adsorvedor de etileno + vácuo. As médias seguidas das mesmas letras maiúsculas nos dias de armazenamento e minúsculas entre os tratamentos, não diferem entre si em nível de 0,05 de probabilidade Tukey

Figura 3. Lesões na casca de bananas 'Prata-Anã' quando submetidas a diferentes tratamentos

Individualmente, as lesões na casca não foram suficientes para concluir se o sachê adsorvedor de etileno foi eficiente. Entretanto, ao observar os parâmetros analisados, como a AT (Figura 1) e a evolução dos teores de açúcares totais e redutores (Figura 4 e 5) pode-se relacionar os resultados obtidos junto ao parâmetro lesões na casca, permitindo uma análise mais conclusiva. Neste sentido e com base na escala de lesões na casca, causada possivelmente por danos mecânicos durante a fase de produção, verificou-se um aumento das lesões no decorrer do experimento, para todos os frutos de todos os tratamentos. Mesmo assim constatou-se que, aos 20 dias de $\mathrm{AR}$, os menores danos apresentados ocorreram nos frutos embalados e submetidos ao vácuo; por outro lado, a partir de 30 dias de AR verificou-se que os frutos armazenados com o sachê adsorvedor e o vácuo apresentaram as menores áreas com lesões na casca, com diferença estatística significativa quando comparados com os demais tratamentos.

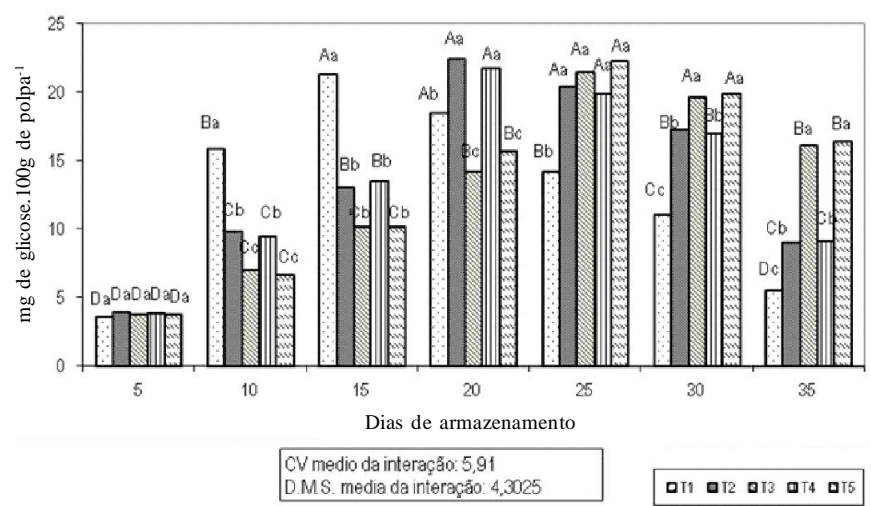

T1 - controle; T2 - embalagem de polietileno de baixa densidade (PEBD); T3 - embalagem de PEBD + adsorvedor de etileno; T4 - embalagem de PEBD + vácuo e T5 - embalagem de PEBD + adsorvedor de etileno + vácuo. As médias seguidas das mesmas letras maiúsculas nos dias de armazenamento e minúsculas entre os tratamentos, não diferem entre si em nível de $5 \%$ de probabilidade Tukey

Figura 4. Açúcares totais em bananas 'Prata-Anã' quando submetidas a diferentes tratamentos

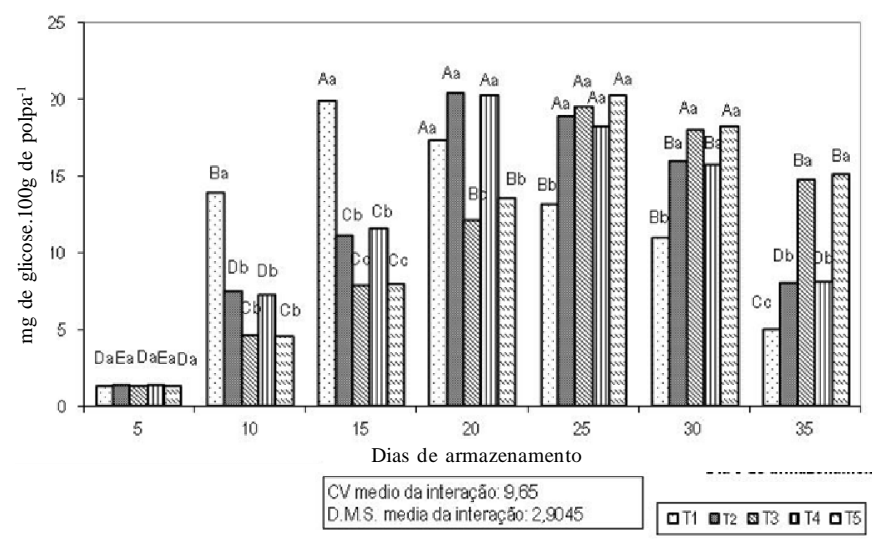

T1 - controle; T2 - embalagem de polietileno de baixa densidade (PEBD); T3 - embalagem de PEBD + adsorvedor de etileno; T4 - embalagem de PEBD + vácuo e T5 - embalagem de PEBD + adsorvedor de etileno + vácuo. As médias seguidas das mesmas letras maiúsculas nos dias de armazenamento e minúsculas entre os tratamentos, não diferem entre si em nível de 0,05 de probabilidade Tukey

Figura 5. Açúcares redutores em bananas 'Prata-Anã' quando submetidas a diferentes tratamentos

Sanches et al. (2004) concluíram, trabalhando na avaliação pós-colheita de danos em bananas 'Nanicão', que os métodos de manuseio utilizados na propriedade rural e o transporte até o centro de distribuição podem favorecer o surgimento do de danos nas bananas em que os resultados revelaram que os mesmos podem duplicar os defeitos leves e quintuplicar os defeitos graves, causando podridão após a climatização, sobremaneira quanto ao aparecimento de lesões ou manchas graves na casca das bananas.

Assim, mesmo com todos os cuidados possíveis em razão da fragilidade das bananas, os frutos podem ser lesionados externamente com facilidade sendo então o AR a $12{ }^{\circ} \mathrm{C}$ um importante fator a ser usado na diminuição do desenvolvimento das lesões em bananas 'Prata' (Coelho et al., 2010). Neste 
sentido pode-se atribuí-las à importância das medidas adotadas para minimizar os danos na casca dos frutos, quando visualizados os frutos embalados em PEBD sob a presença de sachê adsorvedor de etileno visto que a boa aparência, refletida pela menor incidência de lesões na casca, que é essencial para a preferência do consumidor.

O uso da embalagem de PEBD também influenciou estatisticamente os teores de açúcares totais (Figura 4) a partir de 10 dias de AR, sendo que os maiores teores foram observados nos frutos sem o uso da embalagem; no entanto, para os frutos em que a embalagem de PEBD foi utilizada na constituição da AM, houve influência significativa do sachê adsorvedor na evolução dos teores de açúcares totais, durante o AR. Vale ressaltar que no decorrer do período experimental os teores de açúcares totais aumentaram até determinado ponto e, a partir daí, diminuíram. Assim, os pontos de máximo para teores de açúcares totais foram, aos 15 dias, para frutos controle, 20 dias para os frutos embalados com e sem o vácuo e 25 dias para os frutos nos quais se utilizou o sachê de adsorção de etileno, demonstrando a diminuição da velocidade metabólica dos frutos sob a ação do sache adsorvedor; deste modo, acreditase que o processo de amadurecimento das bananas não foi interrompido mas sim retardado, sobretudo quando observado o comportamento metabólico dos frutos expostos ao sachê adsorvedor de etileno, considerado menos acelerado em relação aos frutos sob AM e não influenciados pelo sachê adsorvedor. Por outro lado, ao mesmo tempo em que aos 10, 15 e 20 dias de AR a interconversão de compostos mais polimerizados em açúcares redutores (Figura 5) foi maior nos frutos não expostos ao sachê adsorvedor de etileno.

A partir do $25^{\circ}$ dia de AR esta característica se inverteu indicando que os menores teores de etileno livre (Figura 5) no interior da embalagem apresentaram, neste período, relação direta com o comportamento metabólico dos frutos. De modo geral, durante os 35 dias de AR houve elevação e posterior redução gradual nos teores de açúcares totais. Esta redução pode ser atribuída à diminuição da velocidade de interconversão de amido em açúcares simples, predominantemente em açúcares redutores, como a glicose e frutose (Viviani \& Leal, 2007) tal como a própria utilização dos mesmos como substratos secundários respiratórios.

Inicialmente, os níveis de açúcares redutores (Figura 5) foram semelhantes em todos os tratamentos; a partir do $10^{\circ}$ dia de AR, no entanto, detectou-se diferença estatística significativa entre os frutos do tratamento controle e os demais frutos embalados em PEBD.

Com o decorrer do amadurecimento o comportamento dos frutos foi semelhante: no entanto, aos 15 e 25 dias ocorreu diferença entre os frutos submetidos ao sachê adsorvedor de etileno sendo que, para os frutos do tratamento controle, como consequência do consumo energético de substratos para proporcionar e subsidiar a atividade metabólica foram observados decréscimos nos teores de açúcares redutores até o final do experimento.

Dos 25 aos 30 dias de experimento os frutos acondicionados nas embalagens plásticas apresentaram comportamento semelhante tornando-se diferentes somente no $35^{\circ}$ dia. Portanto, durante o período experimental houve elevação significativa dos teores de açúcares redutores para os frutos embalados sem o sachê adsorvedor de etileno, além de posterior redução ao final do experimento; apesar disto, nos frutos dos tratamentos com o sachê adsorvedor houve manutenção desta característica indicando diminuição do metabolismo e, consequentemente, maior longevidade para os frutos embalados em PEBD.

A concentração de etileno livre no interior das embalagens (Figura 6) foi determinante quanto ao efeito da AM e do sachê adsorvedor e, ainda, quanto ao estádio fisiológico da banana, também condicionado pelo possível atraso no pico climatérico dos frutos. Desta forma é provável que a variação na concentração de etileno no interior das embalagens tenha sido devida ao próprio amadurecimento/senescência dos frutos embalados e submetidos ao sachê adsorvedor; ressalta-se que este fato foi decisivo para a menor atividade metabólica dos frutos durante o experimento, que pode ser comprovada pela menor e mais lenta elevação nos teores de AT (Figura 1) pela redução e pelo retardamento das mudanças nos teores de açúcares totais e redutores (Figuras 4 e 5).

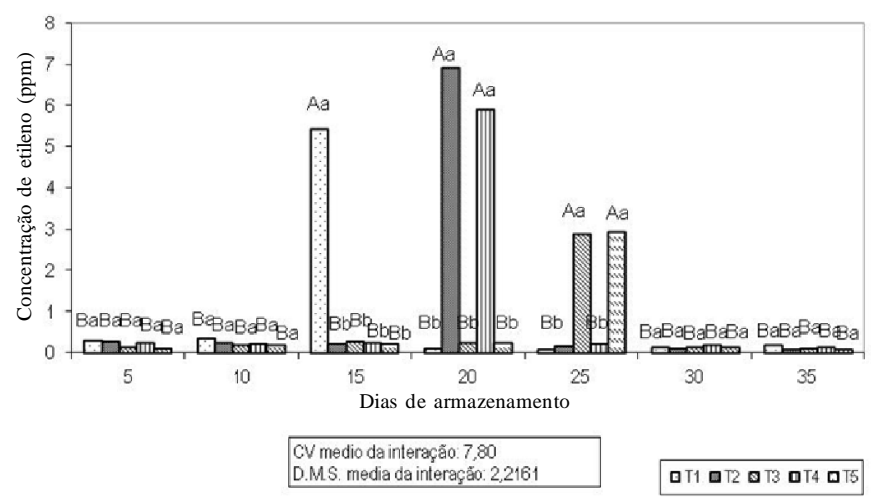

T1 - Controle; T2 - Embalagem de polietileno de baixa densidade (PEBD); T3 - embalagem de PEBD + adsorvedor de etileno; T4 - embalagem de PEBD + vácuo; e T5 - embalagem de PEBD + adsorvedor de etileno + vácuo. As médias seguidas das mesmas letras maiúsculas nos dias de armazenamento e minúsculas entre os tratamentos não diferem entre si em nível de 0,05 de probabilidade Tukey

Figura 6. Concentração de etileno em bananas 'PrataAnã' quando submetidas a diferentes tratamentos

Observou-se ainda que as menores concentrações de etileno foram detectadas no interior das embalagens de PEBD quando acondicionadas com o sachê adsorvedor; pode-se inferir, portanto, sobre a relação fisiológica entre a diminuição dos níveis de etileno livre e a diminuição na velocidade metabólica dos frutos. Resultados semelhantes foram relatados por Neves et al. (2008) ao observarem aumento da vida de prateleira de mangas refrigeradas com a presença do sachê adsorvedor de etileno.

Verificou-se, em bananas, que a remoção e/ou a redução da concentração de etileno durante o AR foi eficiente em prolongar a vida pós-colheita dos frutos (Rocha, 2005). No presente experimento o uso do sachê adsorvedor possivelmente proporcionou a oxidação do etileno liberado pelo fruto durante o amadurecimento prolongando a fase pré-climatérica e a vida pós-colheita. Neste sentido, Brackmann et al. (2006) concluíram que a adsorção do etileno também manteve a melhor qualidade de bananas 'Prata', tanto no armazenamento a 25 como a $12^{\circ} \mathrm{C}$, sendo o principal fator responsável pela diminuição na 
velocidade do amadurecimento. Porém o efeito foi potencializado em concentrações elevadas de $\mathrm{CO}_{2}$ quando os frutos foram armazenados em AM; neste trabalho as bananas 'Prata-Anã' puderam ser armazenadas em AM durante $14 \mathrm{e}$ 21dias, a 25 e $12{ }^{\circ} \mathrm{C}$, respectivamente, sempre com adsorção do etileno. Contudo, ao se fazer uso do AR e da AM, a vida-útil das bananas 'Prata-Anã' foi de no mínimo 30 dias, o que é considerado satisfatório, tendo em vista que o tempo médio decorrido entre a colheita e a comercialização das bananas em Roraima é de aproximadamente 5 dias (Alves et al., 2007).

\section{Conclusões}

A combinação do uso da embalagem de polietileno de baixa densidade com o sachê de permanganato de potássio resultou no retardamento do processo de maturação dos frutos de banana 'Prata-Anã', quando armazenada a $12^{\circ} \mathrm{C}$.

\section{LITERATURA CITADA}

Alves, A. B.; Lima, K. N.; Vieira, B. de A. H. Cultivo da banana em Roraima. Boa Vista: Embrapa Roraima, 2007. 90p.

Antunes, L. E. C.; Duarte Filho, J.: Souza, C. M. de. Conservação pós-colheita de frutos de amoreira-preta. Pesquisa Agropecuária Brasileira, v.38, p.413-419, 2003.

Botrel, N.; Freire Júnior, M.; Vasconcelos, R. M.; Barbosa, H. T. G. Inibição do amadurecimento da banana 'Prata-Anã' com a aplicação do 1 metilciclopropeno. Revista Brasileira de Fruticultura, v.24, p.53-56, 2002.

Brackmann, A.; Steffens, C.; Sestari, I.; Neuwald, A.; Giehl, R. F. H. Armazenamento em atmosfera modificada e controlada de banana 'Prata' com absorção de etileno. Ciência e Agrotecnologia, v.30, p.914-919, 2006.

Brasil. Métodos físico-químicos para análise de alimentos. São Paulo: Instituto Adolfo Lutz, 2008. 1020p.

Campos, R. P.; Valente, J. P.; Pereira, W. E. Conservação póscolheita de banana cv. nanicão climatizada e comercializada em Cuiabá - MT e região. Revista Brasileira de Fruticultura, v.25, p.172-174, 2003.
Coelho, A. F. S.; Dias, M. S. de C.; Rodrigues, M. L. M.; Leal, P. A. M. Controle pós-colheita da antracnose da banana-prata anã tratada com fungicidas e mantida sob refrigeração. Ciência e Agrotecnologia, v.34, p.1004-1008, 2010.

FAO - Food and Agriculture Organization of the United Nations, 2009. <http://faostat.fao.org/site/339/default.aspx/>.07 Mar. 2011.

Moreira, N. X.; Neves, L. C.; Benedette, R. M.; Xavier, V.; Vieites, R. L. Estudo das relações comerciais na feira do produtor em Boa Vista/RR e na feira da banana em Manaus/AM, Academia Roraimense de Ciência - Revista Mens Agitat, v.2, p.59-66, 2007.

Nelson, N. A. A photometric adaptation of somogyi method for the determination of glucose. Journal Biological Chemistry, v.135, p.136-375, 1944.

Neves, L. C.; Benedette, R. M.; Silva, V. X.; Prill, M. A. De S.; Roberto, S. R.; Vieites, R. L. Qualidade pós-colheita de mangas, não-refrigeradas, e submetidas ao controle da ação do etileno. Revista Brasileira de Fruticultura, v.30, p.94-100, 2008.

PBMH-PIF - Programa Brasileiro para a Modernização da Horticultura e Produção Integrada de Frutas. Normas de classificação de banana. São Paulo: CEAGESP, 2006. 67p.

Pinto, L. K. de A.; Martins, M. L. L.; Resende, E. D. de; Almeida, R. F. de; Vitorazi, L.; Pereira, S. M. de F. Influência da atmosfera modificada por filmes plásticos sobre a qualidade do mamão armazenado sob refrigeração. Ciência e Tecnologia de Alimentos, v.26, p.744-748, 2006.

Rocha, A. Uso de permanganato de potássio na conservação pós-colheita de banana 'Prata'. Viçosa: UFV, 2005. 82p. Dissertação Mestrado

Sales, A. N. de; Botrel, N.; Coelho, A. H. R. Aplicação de 1metilciclopropeno em banana 'Prata-Anã' e seu efeito sobre a substâncias pécticas e enzimas pectinolíticas. Ciência e Agrotecnologia, v.28, p.479-487, 2004.

Sanches, J.; Leal, P. A. M.; Saravali, J. H.; Antoniali, S. Avaliação de danos mecânicos causados em banana "Nanicão" durante as etapas de beneficiamento, transporte e embalagem. Engenharia Agrícola, v.24, p.195-201, 2004.

Silva, C. de S.; Lima, L. C.; Santos, H. S.; Camili, E. C.; Vieira, C. R. I. Y.; Martin, C. da S.; Vieites, R. L. Amadurecimento da banana-prata climatizada em diferentes dias após a colheita. Ciência e Agrotecnologia, v.30, p.103-111, 2006.

Viviani, L.; Leal, P. M. Qualidade pós-colheita de banana Prata Anã armazenada sob diferentes condições. Revista Brasileira de Fruticultura, v.29, p.407-413, 2007. 